\title{
Conciliación: requisito de procedibilidad instituido en la Ley Federal del Trabajo*
}

\author{
Verónica Lidia Martínez Martínez**
}

RESUMEN: En el presente artículo se analizan las características de la conciliación $y$ el procedimiento al que ha de sujetarse este mecanismo de solución de controversias que se instituyó en la reforma al apartado $A$ del artículo 123 constitucional, fracción XX y en la reforma a la Ley Federal del Trabajo de 1 o de mayo de 2019, como una instancia previa y obligatoria a la interposición de la demanda laboral ante los tribunales laborales dependientes del Poder Judicial de la Federación y de los poderes judiciales locales. Además en el trabajo se expone la regulación y pronunciamientos de los órganos jurisdiccionales respecto del agotamiento de la conciliación como requisito de procedibilidad de la demanda en la materia laboral.

Palabras clave: Centro Federal de Conciliación y Registro Laboral, Centros de Conciliación Locales, mecanismos alternativos de solución de controversias, conciliación, inexequibilidad, solicitud de conciliación, convenio.
ABSTRACT: This article analyzes the characteristics of the conciliation and the procedure to which this dispute resolution mechanism that was instituted, in the amendment to section $A$ of article 123 constitutional, section $X X$ and in the reform to the Federal Labor Law of 2019, as a prior and obligatory instance to the filing of labor demand before labor courts dependent on the federal judiciary and local judicial powers. In the last part of the work the regulation and pronouncements of the jurisdictional bodies regarding the exhaustion of the conciliation as a requirement of procedural demand in the labor field are exposed.

Keywords: Federal Center for Conciliation and Labor Registration, Local Conciliation Centers, alternative dispute resolution mechanisms, conciliation, non-eligibility, conciliation request, agreement.

SUMARIO: Introducción. 1. Características de la conciliación en materia laboral. 2. La solicitud de conciliación y la audiencia de conciliación. 3. La autoridad conciliadora y su

\footnotetext{
* Artículo recibido el 4 de febrero de 2020 y aceptado para su publicación el 12 de marzo de 2020.

** Doctora y maestra en derecho. Investigadora Nacional del CONACyT. (marb_cap@hotmail.com)
} 
normativa. 4. La conciliación en Sudamérica. 5. Inexequibilidad de la conciliación. Conclusión. Fuentes de consulta.

\section{Introducción}

Como parte de la cultura de la paz en donde se cumplen de manera cabal con los principios de inmediatez, celeridad y economía procesal, los medios o mecanismos alternativos de solución de controversias (MASC)

son aquellos mecanismos que tienen por objeto solucionar los conflictos existentes entre las partes involucradas, de forma directa o a través del nombramiento de un tercero, que puede ser un mediador, el conciliador o el árbitro que coadyuve en la solución alterna de conflictos (Cuadra, 2002:10).

A pesar del impulso legislativo por rescatar y fortalecer la conciliación, en México la realidad mostraba que al 30 de mayo de 2016, "el índice de conciliación de los asuntos individuales en las Juntas Especiales adscritas a la Junta Federal de Conciliación y Arbitraje se situó en 21.6\%" (JFCA, 2016).

Con la finalidad de que la función conciliatoria tuviera un papel preponderante en los asuntos laborales, en el Diario Oficial de la Federación se publicó el 24 de febrero de 2017, el Decreto por el que se reforman y adicionan diversas disposiciones de los artículos 107 y 123 de la Constitución Política de los Estados Unidos Mexicanos, en materia de justicia laboral, que ordena la creación del Centro Federal de Conciliación y Registro Laboral (CFCRL) y de los Centros de Conciliación Locales que funcionaran en cada entidad federativa y en la Ciudad de México para atender y resolver los conflictos laborales a través de una conciliación administrativa obligatoria.

En atención a la reforma constitucional al Sistema de Justicia Laboral; el día 1 de mayo del año 2019 se publicó en el Diario Oficial de la Federación la reforma a la Ley Federal del Trabajo que establece los lineamientos a los que debe sujetarse la conciliación en el ámbito laboral, así como el inicio de funciones de los Centros de Conciliación Laborales dentro de los siguientes plazos:

\begin{tabular}{|l|l|l|}
\hline Plazo máximo & \multicolumn{1}{|c|}{ Fecha } & \multicolumn{1}{|c|}{ Acción } \\
\hline 180 días & $\begin{array}{l}\text { Octubre de 2019 } \\
\text { No se cumplió en el plazo establecido. } \\
\text { Este ordenamiento se publicó en el } \\
\text { Diario Oficial de la Federación el día 6 de } \\
\text { enero de 2020. }\end{array}$ & $\begin{array}{l}\text { Expedición de la Ley Orgánica del } \\
\text { Centro Federal de Conciliación y } \\
\text { Registro Laboral. }\end{array}$ \\
\hline 2 años & 2 de mayo de 2021 & $\begin{array}{l}\text { Inicio de funciones del CFCRL en } \\
\text { materia de registro sindical y de } \\
\text { contratos colectivos. }\end{array}$ \\
\hline 3 años & 2 de mayo de 2022 & $\begin{array}{l}\text { Inicio de funciones de los Centros de } \\
\text { Conciliación Locales y los Tribunales } \\
\text { Locales. }\end{array}$ \\
\hline años & $\begin{array}{l}\text { Inicio de funciones del CFCRL para } \\
\text { tramitar las solicitudes de conciliación. } \\
\text { Inicio de funciones de los tribunales } \\
\text { federales. }\end{array}$ \\
\hline
\end{tabular}


Cuadro 1. Plazos máximos para que la reforma procesal se cumplimente en materia de conciliación. Los referidos plazos deben computarse a partir de la entrada en vigor del Decreto por el que se reforman, adicionan y derogan diversas disposiciones de la Ley Federal del Trabajo, de la Ley Orgánica del Poder Judicial de la Federación, de la Ley Federal de la Defensoría Pública, de la Ley del Instituto del Fondo Nacional de la Vivienda para los Trabajadores y de la Ley del Seguro Social, en materia de Justicia Laboral, Libertad Sindical y Negociación Colectiva, publicado en el Diario Oficial de la Federación de 1o de mayo de 2019.

Elaborado por la autora.

Bajo este panorama, el presente trabajo tiene como objetivo analizar la figura de la conciliación como instancia prejudicial de carácter obligatorio, para lo cual se emplea el método analítico en los primeros cuatro apartados. De esta manera, en primer lugar, se realiza un estudio de las principales características de la conciliación en materia laboral, así como de la solicitud y audiencia de conciliación que se analizan bajo el numeral segundo de la obra.

En el apartado tercero es motivo de análisis la regulación de la autoridad conciliadora. Por supuesto, bajo el método comparado, se desarrolla el penúltimo apartado de esta obra por contener el estudio de la conciliación en los países sudamericanos que la instituyen como instancia prejudicial. De igual manera, con el auxilio del método comparado se analiza en la parte final del trabajo, la inexequibilidad de la conciliación en Colombia a partir las resoluciones emitidas por su máximo Tribunal Constitucional que sirven de marco teórico a la presente obra para comprender los inconvenientes de instaurar la conciliación prejudicial con carácter obligatorio.

\section{Características de la conciliación en materia laboral}

La palabra conciliación deriva etimológicamente del "latín conciliatio, que proviene, a su vez, del verbo conciliare que significa concertar, componer o poner de acuerdo a dos o más partes que se debaten en una controversia de intereses" (Larousse, 1993:324). La conciliación, como "mecanismo de resolución de conflictos a través del cual dos o más personas gestionan por sí mismas la solución de sus diferencias, con ayuda de un tercero neutral y calificado, denominado conciliador" (Ojeda, 2017:109), en materia laboral presenta las siguientes características:

a. Nominada. La conciliación se encuentra prevista en el artículo 123 constitucional, apartado $A$, fracción $X X$; en tanto, que su regulación y la del procedimiento para llevarla a cabo se consigna en los artículos 684-A a 684-E de la Ley Federal del Trabajo.

b. Es un requisito de procedibilidad en el ámbito laboral. Es obligatoria su interposición para que pueda accederse a la vía jurisdiccional ante los tribunales laborales. Con esta medida se privilegia que tribunales laborales concentren su atención en las tareas jurisdiccionales, propias de su nueva responsabilidad.

c. Es de carácter extrajudicial. La conciliación se efectúa ante los conciliadores adscritos a los centros de conciliación federal y locales.

d. Su finalidad es soslayar la interposición de las demandas laborales y solucionar la controversia con el máximo de celeridad posible.

e. Tiene lugar en sede administrativa y se lleva a cabo por instituciones. En el orden local, la función conciliatoria estará a cargo de los Centros de Conciliación, especializados e 
imparciales que se instituyan en las entidades federativas. En el orden federal, la función conciliatoria estará a cargo de un organismo descentralizado. Al organismo descentralizado también le corresponderá, el registro de todos los contratos colectivos de trabajo y las organizaciones sindicales, así como todos los procesos administrativos relacionados.

f. El convenio celebrado en el acto conciliatorio de ser ratificado por las partes y aprobado por la autoridad tiene el carácter de sentencia.

g. De acuerdo con el artículo 685 Ter de la Ley Federal del Trabajo, a las partes se les exime de acudir a la instancia conciliatoria y de exhibir la constancia de no conciliación, en los siguientes conflictos:

a. Discriminación en el empleo y ocupación por embarazo, así como por razones de sexo, orientación sexual, raza, religión, origen étnico, condición social o acoso u hostigamiento sexual.

b. Designación de beneficiarios por muerte.

c. Prestaciones de seguridad social por riesgos de trabajo, maternidad, enfermedades, invalidez, vida y guarderías. ${ }^{1}$

d. La tutela de derechos fundamentales y libertades públicas, ambos de carácter laboral, entendidos en estos rubros los relacionados con la libertad de asociación, libertad sindical y el reconocimiento efectivo de la negociación colectiva; trata laboral, así como trabajo forzoso y obligatorio y el trabajo infantil. Para la actualización de estas excepciones es necesario acreditar la existencia de indicios que generen al tribunal la razonable sospecha, apariencia o presunción de que se están vulnerando alguno de estos derechos.

e. Pérdida de la mayoría de los trabajadores en el Contrato Colectivo de Trabajo La disputa de la titularidad de contratos colectivos o contratos-Ley.

f. La impugnación de los estatutos de los sindicatos o su modificación.

g. Cuando se impugnen procedimientos de elección de las directivas sindicales.

\section{La solicitud de conciliación y la audiencia de conciliación}

El procedimiento de conciliación prejudicial en materia laboral, que no deberá exceder de cuarenta y cinco días naturales, iniciará con la presentación de la solicitud. De acuerdo con el artículo 684-C de la Ley Federal del Trabajo, para su admisión la solicitud se deberá reunir los requisitos siguientes:

a. Indicar el nombre de la persona y su Clave Única de Registro de Población (CURP).

b. Proporcionar domicilio dentro del lugar en que se ubique el centro de conciliación al que acuda.

c. Mencionar el nombre de la persona, sindicato o empresa a quien se citará para la conciliación prejudicial, además de señalar su domicilio. Cuando el trabajador ignore el nombre de su empleador o de la empresa, basta con señalar el domicilio donde prestó o presta sus servicios.

d. Es necesario adjuntar la identificación oficial del solicitante.

\footnotetext{
${ }^{1}$ No se exceptúa de la conciliación los seguros de retiro, cesantía en edad avanzada y vejez (RCV), así como el de prestaciones sociales.
} 
La solicitud de conciliación podrá formularse por escrito, mediante comparecencia de los interesados o de manera electrónica. Es obligación del personal de los centros de conciliación auxiliar a los interesados en la presentación de la solicitud de conciliación, además de proporcionar asesoría jurídica sobre los derechos laborales, sus plazos de prescripción y el procedimiento para solucionar el conflicto.

Al recibir la solicitud de conciliación, si la autoridad conciliadora no es competente, procederá a remitir la solicitud vía electrónica al centro de conciliación competente dentro de las siguientes veinticuatro horas siguientes a su recepción y a notificar al solicitante para que acuda ante ella a continuar el procedimiento. Por el contrario, al decretarse la competencia del centro de conciliación, la solicitud será radicada con un número de identificación único, se designará por turno una sala de conciliación, además de señalarse día y hora para que tenga verificativo la audiencia de conciliación a efectuarse dentro de los quince días siguientes a la recepción de la solicitud.

Como medio de notificación de las actuaciones que se realicen en el procedimiento de conciliación prejudicial a las partes se les asignará un buzón electrónico, pero el citatorio en donde se consigne el día y la hora en que tendrá verificativo la audiencia de conciliación deberá notificarse al patrón de manera personal por lo menos con cinco días de anticipación a la audiencia.

La audiencia de conciliación podrá tener lugar dentro de los cinco días hábiles siguientes a la presentación de la solicitud, cuando lo requiera el solicitante y entregue el citatorio a la persona que corresponda. Cuando la solicitud de conciliación se presente de manera personal por las partes involucradas en el conflicto laboral, conforme a la fracción VI del artículo 684-E de la Ley Federal del Trabajo, es posible que la audiencia de conciliación tenga verificativo en ese momento o se les notifique de inmediato la fecha y hora de su celebración que ha de tener lugar dentro de un plazo máximo de cinco días contados a partir de la fecha de presentación de la solicitud.

Conforme al artículo 684-E de la Ley Federal del Trabajo, en la audiencia de conciliación las partes deberán identificarse con cualquier documento oficial al comparecer en la audiencia de conciliación, cuya dirección se encuentra a cargo del conciliador. En caso de que el solicitante, no cuente con identificación oficial, podrá ser identificado por otros medios de que disponga el Centro de Conciliación.

Por regla general, el trabajador solicitante de la instancia conciliatoria deberá acudir de manera personal a la audiencia, aunque puede asistir acompañado por una persona de su confianza, a quién en ningún caso, se le reconocerá como apoderado, por tratarse de un procedimiento de conciliación y no de un juicio. El trabajador podrá ser asistido por un licenciado en derecho, abogado o un Procurador de la Defensa del Trabajo.

De acuerdo con la fracción XII del artículo 684-E de la Ley Federal del Trabajo, el procedimiento de conciliación se llevará con el representante o apoderado del citado cuando en la solicitud de conciliación se manifieste la existencia de acoso sexual, discriminación u otros actos de violencia. Para soslayar la revictimización, la autoridad conciliadora tomará las medidas conducentes para evitar que la presunta víctima y la 
persona o personas a quienes se atribuyen los actos de violencia se reúnan o encuentren en un mismo espacio.

Por su parte, el patrón deberá asistir personalmente o por conducto de representante con facultades suficientes para obligarse en su nombre. Con la finalidad de dar por terminada la controversia laboral, al empleador le corresponde formular una propuesta de arreglo conciliatorio, que en caso de ser aceptada por el trabajador, dará lugar a la celebración de un convenio que al adquirir la condición de cosa juzgada, tendrá la calidad de un título para iniciar acciones ejecutivas sin necesidad de ratificación, por lo que cualquiera de las partes podrá promover su cumplimiento mediante el procedimiento de ejecución de sentencia que prevé la Ley Federal del Trabajo, ante el Tribunal competente. Al celebrar convenio, las Autoridades Conciliadoras entregarán copia certificada del mismo para cada una de las partes y copia certificada de las actas donde conste el cumplimiento del convenio.

La autoridad conciliadora es responsable de que el convenio que se celebre cumpla con los requisitos y prestaciones laborales aplicables al caso concreto. De acuerdo a lo dispuesto en el último y penúltimo párrafo del artículo 684-E de la Ley Federal del Trabajo, cuando las partes den cumplimiento voluntario al convenio celebrado corresponderá a la autoridad conciliadora certificar que el trabajador recibe de manera personal la cantidad de dinero que se estipuló en el convenio suscrito. En caso de que las partes establezcan pagos diferidos, en una o más parcialidades a cubrir en fecha diversa a la celebración del convenio, deberá fijarse una pena convencional para el caso de incumplimiento. La cantidad por concepto de pena convencional, no podrá ser menor del salario diario del trabajador por cada día que transcurra sin que se dé cumplimiento total al convenio suscrito.

Por el contrario, de conformidad con la fracción IX del artículo 684-E de la Ley Federal del Trabajo, de no haber arreglo conciliatorio, el Centro de Conciliación emitirá constancia que justifica el agotamiento de la conciliación prejudicial. No obstante lo anterior, a juicio del juez laboral de existir causa justificada que impida la comparecencia de una de las partes a la audiencia de conciliación, provocará, que dentro de los cinco días siguientes se señale nuevo día y hora para su realización. La parte que comparezca a la audiencia quedará notificada en este acto, mientras que al incompareciente se le notificará a través del boletín del Centro de Conciliación y, en su caso, por buzón electrónico.

De igual manera, podrá celebrarse una nueva audiencia de conciliación cuando lo soliciten las partes por no haber llegado a un acuerdo. Por el contrario, la injustificada incomparecencia a la audiencia de conciliación producirá los siguientes efectos:

\begin{tabular}{|c|l|}
\hline Incomparecencia injustificada & \multicolumn{1}{|c|}{ Efectos } \\
\hline Empleador & $\begin{array}{l}\text { Multa, cuyo monto oscila entre cincuenta y cien } \\
\text { veces la Unidad de Medida y Actualización (UMA) y } \\
\text { se emite la constancia de haber agotado la etapa de } \\
\text { conciliación. Para el año } 2020 \text { el valor de la UMA es } \\
\text { de } \$ 86.88 \text { pesos, por lo tanto, la sanción podrá ser } \\
\text { por un importe de } \$ 4,344.00 \text { a } \$ 8,688.00\end{array}$ \\
\hline
\end{tabular}


Trabajador solicitante

Se archiva el asunto sin emisión de constancia de haber agotado la conciliación

En ambos casos se reanudan los plazos de prescripción, dejando a salvo los derechos del trabajador para solicitar nuevamente la conciliación.

Cuadro 2. Efectos de la incomparecencia a la conciliación

Elaborado por la autora con base en el artículo 684-E la Ley Federal del Trabajo.

Cuando el notificador no logre notificar a la persona, empresa o sindicato a citar, a pesar de haberlo intentado, la autoridad conciliadora dará por terminado el procedimiento de conciliación prejudicial con la emisión de la constancia, pero dejará a salvo los derechos de solicitante para promover juicio ante el tribunal competente.

\section{La autoridad conciliadora y su normativa}

El CFCRL y de los Centros de Conciliación que funcionaran en cada entidad federativa y en la Ciudad de México serán los encargados de substanciar el procedimiento de la conciliación a la que deberán acudir los trabajadores y patrones antes de presentar demanda ante los Tribunales Laborales.

Al instituirse como un organismo público descentralizado del Gobierno Federal, de acuerdo con el artículo 10 de la Ley Orgánica del Centro Federal de Conciliación y Registro Laboral, el CFCRL se integrará por la Dirección General y la Junta de Gobierno. Por su parte, el artículo 590-D de la Ley Federal del Trabajo dispone que la Junta de Gobierno estará conformado de la siguiente manera:

a. El titular de la Secretaría del Trabajo y Previsión Social como miembro propietario o su suplente, quien fungirá como Presidente de dicha Junta de Gobierno;

b. El titular de la Secretaría de Hacienda y Crédito Público como miembro propietario o su suplente;

c. El titular del Instituto Nacional de Transparencia, Acceso a la Información y Protección de Datos Personales como miembro propietario o su suplente;

d. El Presidente del Instituto Nacional de Estadística y Geografía como miembro propietario o su suplente, $y$

e. El Presidente del Instituto Nacional Electoral como miembro propietario o su suplente.

De la anterior transcripción, se desprende que en la Junta de Gobierno carecen de representatividad los interlocutores sociales que son necesarios cuando se trata de resolver los conflictos obrero-patronales, de acuerdo con la Recomendación sobre la conciliación y el arbitraje voluntarios (número 92) de la Organización Internacional del Trabajo (OIT). La estructura tripartita de la OIT, como órgano especializado del Sistema de las Naciones Unidas en materia laboral y de seguridad social, en la cual trabajadores y empleadores tienen el mismo derecho a voto que los gobiernos durante las deliberaciones de los órganos principales de la OIT, garantiza que al verse reflejadas las opiniones de los interlocutores sociales en las normas, políticas y programas de la Organización se genere la aceptación para su cumplimiento y aplicabilidad.

Por su parte, los Centros de Conciliación Laborales que funcionarán en cada entidad federativa y en la Ciudad de México tendrán un Órgano de Gobierno integrado por los 
titulares de las dependencias u organismos públicos que señalen las legislaciones locales. Los estados de Campeche, Coahuila de Zaragoza, Chiapas, Estado de México, Guanajuato, Nuevo León, Morelos, Nayarit, Oaxaca, Quintana Roo e Hidalgo, para crear los centros de conciliación laborales, en cumplimiento a lo dispuesto en el artículo segundo transitorio del Decreto por el que se reforman y adicionan diversas disposiciones de los artículos 107 y 123 de la Constitución Política de los Estados Unidos Mexicanos, en materia de justicia laboral, reformaron las siguientes disposiciones:

ENTIDAD FEDERATIVA

\begin{tabular}{|c|c|}
\hline CAMPECHE & $\begin{array}{l}\text { Capítulo XV Ter de la Constitución Política del Estado de } \\
\text { Campeche. }\end{array}$ \\
\hline COAHUILA & $\begin{array}{l}\text { Artículo } 85 \text { de la Constitución Política del Estado de Coahuila } \\
\text { Zaragoza. }\end{array}$ \\
\hline CHIAPAS & $\begin{array}{l}\text { De acuerdo con el artículo segundo transitorio del Decreto } \\
\text { número } 169 \text { publicado en el Periódico Oficial del Estado número } \\
353 \text {, de } 2 \text { de marzo de 2018, "las funciones del Centro de } \\
\text { Conciliación Laboral de Chiapas iniciarán una vez que lo establezca } \\
\text { la Ley Federal del Trabajo". }\end{array}$ \\
\hline ESTADO DE MÉXICO & $\begin{array}{l}\text { Artículo } 88 \text { de la Constitución Política del Estado Libre y Soberano } \\
\text { de México. }\end{array}$ \\
\hline GUANAJUATO & $\begin{array}{l}\text { Último párrafo del artículo } 80 \text { de la Constitución Política para el } \\
\text { Estado de Guanajuato. }\end{array}$ \\
\hline HIDA & Artículo 9 Ter de la Constitución Política para el Estado de Hidalgo. \\
\hline MOF & $\begin{array}{l}\text { Se adiciona el Capítulo VIII denominado "Del Centro de } \\
\text { Conciliación Laboral del Estado de Morelos" a la Constitución } \\
\text { Política del Estado Libre y Soberano de Morelos. }\end{array}$ \\
\hline NAYARIT & $\begin{array}{l}\text { Fracción VII del artículo } 7 \text { de la Constitución Política del Estado } \\
\text { Libre y Soberano de Nayarit. }\end{array}$ \\
\hline NUEVO LEÓN & $\begin{array}{l}\text { Artículos tercero, cuarto, quinto y sexto transitorios del Decreto } \\
361 \text { publicado en el Periódico Oficial del Estado, de } 4 \text { de abril de } \\
2018 \text { que adicionó la Constitución Política del Estado Libre y } \\
\text { Soberano de Nuevo León. }\end{array}$ \\
\hline OAXACA & $\begin{array}{l}\text { Apartado B del artículo } 114 \text { de la Constitución Política del Estado } \\
\text { Libre y Soberano de Oaxaca. }\end{array}$ \\
\hline QUINTANA ROO & $\begin{array}{l}\text { Artículo } 92 \text { de la Constitución Política del Estado Libre y Soberano } \\
\text { de Quintana Roo. }\end{array}$ \\
\hline
\end{tabular}

Cuadro 3. Modificaciones constitucionales estatales para cumplimentar la reforma y adición a diversas disposiciones de los artículos 107 y 123 de la Constitución Política de los Estados Unidos Mexicanos, en materia de justicia laboral,

Elaborado por la autora con base en los textos constitucionales de los estados de Campeche, Coahuila de Zaragoza, Chiapas, Estado de México, Guanajuato, Nuevo León, Morelos, Nayarit, Oaxaca, Quintana Roo e Hidalgo. 
De manera general, en las normas constitucionales locales se regulan los aspectos referentes a la integración de los centros de conciliación laborales, así como los requisitos, atribuciones y responsabilidades que deben reunir los titulares de estos centros de conciliación.

A pesar de que es inexistente la reforma a la Constitución Política del Estado de Chihuahua, el 17 de febrero de 2018 se publicó en esta entidad federativa la Ley del Centro de Conciliación Laboral que junto con la Ley Orgánica del Centro de Conciliación Laboral del Estado de Campeche y la Ley del Centro de Conciliación Laboral del Estado de Hidalgo² crean los Centros de Conciliación Laboral de los Estados de Chihuahua, Campeche e Hidalgo, bajo la naturaleza jurídica de organismos públicos descentralizados.

El resto de las legislaturas de las entidades federativas han incurrido en una omisión legislativa o normativa absoluta ante la falta de reforma a sus textos constitucionales y leyes secundarias para implementar la reforma en materia de justicia laboral en la que el Poder Reformador de la Constitución mexicana les otorgó el mandato constitucional (Verfassungsauftrag) de ejercicio expreso, consistente en realizar las adecuaciones legislativas para que se instituyan los centros de conciliación laborales a los que se les encomendó la función conciliatoria previa al procedimiento laboral correspondiente que ha de seguirse ante los tribunales laborales dependientes de los poderes judiciales locales.

\section{La conciliación en Sudamérica}

El agotamiento previo y obligatorio de la conciliación como requisito para que sea admitida la demanda por parte de los órganos jurisdiccionales, no es un tema novedoso en Sudamérica. Costa Rica y Perú reformaron sus códigos de trabajo para dejar sin efectos la obligatoriedad de la conciliación como requisito de procedibilidad para acceder a la vía judicial.

La reforma procesal laboral introducida por la Ley número 9343 se aprobó el 9 de diciembre de 2015 en la Asamblea Legislativa y entró en vigor el 25 de julio del 2017. Bajo este tenor, conforme al artículo 459 de la Ley № 9343, es facultativo para los trabajadores y patrones someter la solución de sus conflictos, de forma previa a la intervención de los órganos jurisdiccionales, a conciliadores o mediadores privados o del Ministerio de Trabajo y Seguridad Social. La solicitud de conciliación, interrumpirá la prescripción, la cual tampoco correrá mientras se ventila la cuestión en esa sede, por un plazo máximo de tres meses.

La conciliación también puede llevarse a cabo ante el juzgador, juez conciliador especializado del despacho o del respectivo centro de conciliación judicial. En este caso, el proceso se mantendrá en suspenso hasta por tres meses, lapso durante el cual no correrá plazo alguno de prescripción.

Por su parte, en Perú se reformó la Quinta Disposición Complementaria de la Ley № 29497, publicada el 15 de enero de 2010 y vigente a partir del mes de julio de ese mismo,

\footnotetext{
${ }^{2}$ La Comisión Nacional de Derechos Humanos impugnó la Ley del Centro de Conciliación Laboral del Estado de Hidalgo por considerar que vulnera el derecho de igualdad y el principio de no discriminación, toda vez que su artículo 14 excluye a los mexicanos por naturalización de la posibilidad de acceder al cargo de director general del Centro de Conciliación Laboral.
} 
que dispone que la conciliación administrativa se encuentra a cargo del Ministerio de Trabajo y Promoción del Empleo, el cual proporciona los medios técnicos y profesionales para hacerla factible. De acuerdo con esta normativa las principales características de este tipo de conciliación son las siguientes:

a. Es un mecanismo alternativo de solución de conflictos.

b. Es facultativa para el trabajador y obligatoria para el empleador.

c. Es gratuita.

El otro tipo de conciliación que se instituye en Perú es la conciliación extrajudicial. De acuerdo con el artículo 5 de la Ley número 26872 este tipo de conciliación es un mecanismo alternativo para la solución de conflictos, por el cual las partes acuden ante un Centro de Conciliación o al Juzgado de Paz Letrado a fin que se les asista en la búsqueda de una solución consensual al conflicto. La materia laboral es conciliable cuando se respeta el carácter irrenunciable de los derechos del trabajador reconocidos por la Constitución Política del Perú y la ley, además de llevarse a cabo la conciliación en los Centros de Conciliación Gratuitos del Ministerio de Justicia, Ministerio de Trabajo y Promoción del Empleo y en los Centros de conciliación privados.

La obligatoriedad del agotamiento previo de la conciliación quedó sin efectos al promulgarse el 28 de junio de 2008 el Decreto Legislativo № 1070 que dispuso que la conciliación establecida no resulta exigible a efectos de calificar la demanda en materia laboral, por lo que es potestad de las partes recurrir a este medio de solución de controversias. La anterior normatividad entró en vigor de manera progresiva en los diferentes Distritos Conciliatorios en términos de lo establecido en el Calendario Oficial aprobado mediante Decreto Supremo con excepción de los distritos conciliatorios de Lima, Trujillo y Arequipa, así como el Distrito Judicial del Cono Norte de Lima, salvo la provincia de Canta, en los cuales se determinó su aplicación a los sesenta días calendario de su publicación.

En el polo opuesto en Argentina, la Ley $N^{\circ} 24.624$ y su norma reglamentaria, el Decreto Ley $N^{\circ} 1169 / 96^{3}$ instituyen y regulan un régimen de conciliación laboral obligatorio y previo a la demanda judicial que se interpone en los reclamos individuales y pluriindividuales sobre conflictos de derecho correspondientes a la competencia de la Justicia Nacional del Trabajo.

Conforme a los citados ordenamientos, en Argentina la conciliación prejudicial obligatoria está a cargo del Servicio de Conciliación Laboral Obligatoria (SECLO) del Ministerio de Trabajo y Seguridad Social, aunque el Registro de los Conciliadores esté a cargo del Ministerio de Justicia. EI SECLO practicará el sorteo del conciliador y fijará la fecha y hora de la primera audiencia ante éste, circunstancias ambas que notificará al reclamante o a su apoderado o representante; al requerido o requeridos y al conciliador.

Las partes deberán concurrir a las audiencias en forma personal. La persona debidamente citada que no compareciera a una audiencia tendrá un plazo de cinco días con posterioridad a la misma para justificar su incomparecencia ante el conciliador. De resultar

\footnotetext{
${ }^{3}$ Publicado en el Boletín Oficial de 18 de octubre de 1996.
} 
justificada la inasistencia, el conciliador dispondrá la aplicación de una multa. Cuando el requerido fuera debidamente citado y no compareciera a las audiencias en dos oportunidades sucesivas, sin que su incomparecencia fuera justificada, el conciliador dará por finalizado el trámite de conciliación, se levantará la correspondiente acta y quedará expedita la vía judicial ordinaria.

El trámite conciliatorio concluirá cuando el reclamante que haya sido notificado, no compareciera de manera injustificada a las audiencias en dos oportunidades sucesivas. En este supuesto, el reclamante deberá iniciar nuevamente su reclamo ante el SECLO para cumplir con el procedimiento de instancia obligatoria de conciliación laboral.

De alcanzarse un acuerdo conciliatorio, el conciliador presentará las actuaciones al SECLO dentro de los dos días posteriores a su firma, recibiendo una constancia de recepción que podrá insertarse en una copia del acuerdo. A partir del día siguiente de esta presentación se contará el plazo de tres días para que el Ministerio de Trabajo y Seguridad Social se pronuncie sobre la homologación del acuerdo conciliatorio mediante resolución del titular del SECLO, que será notificada al conciliador.

De igual manera, en Uruguay, el artículo 3 de la Ley № 18.847, de Abreviación de los Procesos Laborales ordena que antes de iniciarse juicio en materia laboral, deberá agotarse la conciliación previa ante el Centro de Negociación de Conflictos Individuales de Trabajo en la ciudad de Montevideo o ante la Oficina de Trabajo dependiente del Ministerio de Trabajo y Seguridad Social en el interior de la República, según corresponda al domicilio del empleador o al lugar en el que se cumplieron las prestaciones. Cuando en la jurisdicción territorial del Tribunal competente no existan oficinas de trabajo zonales, el reclamante quedará exonerado de tentar la conciliación.

De acuerdo a la Ley 18.847 de 8 de diciembre de 2011, modificativa de la Ley 18.572 de 8 de octubre de $2019,{ }^{4}$ la solicitud de inicio del procedimiento conciliatorio deberá realizarse por escrito presentado por el interesado o por apoderado, asistido de abogado, salvo que la reclamación fuera por sumas inferiores al equivalente de veinte unidades reajustables. En dicha solicitud deberán indicarse con precisión los hechos que fundamentan el reclamo, así como el detalle y el monto de las prestaciones reclamadas.

Conforme a la Ley № 18.847, la audiencia de conciliación se realizara en una única audiencia. Si la empresa citada no se presenta a la audiencia, dicha omisión constituirá presunción simple en su contra en el juicio ulterior. En todo caso, el trámite de conciliación administrativa debe culminar dentro de los treinta días contados desde la solicitud, por lo que el trabajador podrá solicitar una constancia con la cual podrá presentar directamente la demanda judicial ante el juzgado de trabajo que corresponda de no concluirse la conciliación dentro del plazo establecido.

De alcanzarse un acuerdo y la empresa no lo cumple, el acuerdo incumplido se asimila a una sentencia de condena y el trabajador podrá iniciar el proceso de ejecución.

\section{Inexequibilidad de la conciliación}

\footnotetext{
${ }^{4}$ La Ley 18.572 entró en vigor el 18 de octubre de 2019.
} 
Donde mayor controversia ha generado el agotamiento de la conciliación obligatoria en materia laboral, es en Colombia. El artículo 39 de la Ley 23 de 1991 instituyó a la conciliación en un presupuesto procesal previo para poder demandar y acceder a la administración de justicia. La Corte Constitucional de Colombia empezó por aceptar la constitucionalidad de la conciliación en el ámbito laboral como requisito de procedibilidad, de cumplirse con los siguientes presupuestos (Corte Constitucional de Colombia, 17 de marzo de 1999: Sentencia C-160/99):

a. Que se tengan los medios materiales y personales suficientes para atender las peticiones de conciliación que se presentan por quienes están interesados en poner fin a un conflicto laboral.

b. Que se especifique de manera concreta cuáles son los conflictos susceptibles de ser conciliados, y cuáles por exclusión naturalmente no la admiten.

c. Que se defina, en el caso de los conflictos que involucran a la Nación, entidades públicas descentralizadas, instituciones o entidades de derecho social sí, además, del agotamiento de la vía gubernativa se requiere agotar la conciliación, o si ésta sustituye el procedimiento no relativo a dicho agotamiento.

d. Que se establezca que la petición de conciliación, interrumpe la prescripción de la acción y se determine un tiempo preciso durante el cual se debe intentar la conciliación, expirado éste las partes tienen libertad para acceder a la jurisdicción.

Por su parte, la Ley 640 de 5 de enero de 2001, por la cual se modifican normas relativas a la conciliación y se dictan otras disposiciones, ${ }^{5}$ que entró en vigor el 5 de enero de 2002, también instituyó a la conciliación como requisito de procedibilidad para acceder a la administración de justicia, además de establecer a los centros de conciliación y sus normas de administración, operación y funcionamiento. Al pronunciarse sobre la constitucionalidad de esta normativa, el 22 de agosto de 2001 la Sala Plena de la Corte Constitucional de Colombia en la Sentencia C-893/2001 decretó la inexequibilidad de la conciliación en materia laboral, por las siguientes razones:

a. El legislador no puede establecer la conciliación prejudicial como un requisito obligatorio de procedibilidad para acudir ante la jurisdicción laboral, toda vez que los mecanismos alternativos de solución de conflictos en general, y de la conciliación laboral, en particular, son de naturaleza voluntaria.

b. La conciliación laboral como requisito de procedibilidad quebranta el principio constitucional contenido en el artículo 53 de la Constitución Política de Colombia, según el cual, corresponde a la Ley tener en cuenta la facultad de los trabajadores para transigir y conciliar sobre derechos inciertos y discutibles ya que aún cuando el trabajador tenga la certeza de que le asiste un derecho indiscutible y cierto, y realmente ese derecho tenga tal carácter, no lo puede ejercitar directamente sin antes haberse sometido al procedimiento conciliatorio previo y obligatorio.

c. La conciliación laboral como requisito de procedibilidad viola el carácter social de los derechos del trabajador y la especial protección que debe darle el Estado a éstos, lo cual exige que el acceso a la justicia no pueda estar diferido ni obstaculizado por una condición de procedibilidad impuesta aún contra la voluntad del beneficiario, con mayor razón si para ese trámite previo al proceso se contempla la posibilidad de que el titular del derecho tenga en ocasiones que sufragar de su propio peculio expensas significativas para poder accionar ante los jueces.

d. No hay cosa juzgada constitucional sobre la conciliación como requisito de procedibilidad en materia

\footnotetext{
${ }^{5}$ Publicada en el Diario oficial de 24 de enero de 2001.
} 
laboral en la Sentencia C-160 de 1999, sin embargo, no se pretende desconocer la necesidad planteada en la sentencia en el sentido de que existan unas condiciones materiales mínimas para la implementación de la conciliación como mecanismo alternativo de solución de conflictos, siempre y cuando en el diseño de esta herramienta el legislador además tenga presente las características constitucionales que le atribuye el artículo 116 de la Carta Política cuando indica que las partes son quienes deben habilitar al conciliador para que pueda ejercer sus funciones.

De acuerdo con las anteriores consideraciones, es que se decretó la inconstitucionalidad del artículo 39 de la Ley 640 de 2001 que estableció el requisito de procedibilidad en asuntos laborales. El 28 de mayo de 2002 se dictó la Sentencia C-417/2002 en la que con base en la Sentencia 893/2001 decretó también la inconstitucionalidad del requisito de procedibilidad en el ámbito laboral.

Como resultado de la declaratoria de inexequibilidad, en el caso de la conciliación en materia laboral, la Ley 712 de $2001^{6}$ en su artículo 14 que modifica el artículo 26 del Código Procesal del Trabajo y de la Seguridad Social, dispone que la demanda deberá ir acompañada de los siguientes anexos:

1. El poder.

2. Las copias de la demanda para efecto del traslado, tantas cuantos sean los demandados.

3. Las pruebas documentales y las anticipadas que se encuentren en poder del demandante.

4. La prueba de la existencia y representación legal, si es una persona jurídica de derecho privado que actúa como demandante o demandado.

5. La prueba del agotamiento de la reclamación administrativa si fuere el caso.

6. La prueba del agotamiento del requisito de procedibilidad de que trata la ley 640 de 2001, cuando ella lo exija.

La anterior disposición instituye a la conciliación como requisito de procedibilidad de la demanda cuando la normativa lo exija, como acontece en la materia civil, cuya constitucionalidad ha sido reconocida por la Corte Constitucional de Colombia, en contraposición al ámbito de lo laboral, al decretar la inexequibilidad del artículo 39 de la Ley 640 de 2001.

\section{Conclusión}

La reforma a la Ley Federal de Trabajo del 10 de mayo de 2019, que instituye en materia laboral, a la conciliación como requisito previo y obligatorio para acceder a la vía jurisdiccional, siguiendo los modelos latinoamericanos y sudamericanos, aún no entra en vigor. A nivel federal y en el ámbito local se está construyendo el marco normativo que ha de regular el procedimiento de conciliación, así como la integración, atribuciones y obligaciones de los centros de conciliación en materia laboral.

La modificación y expedición de los ordenamientos legales que materialicen la reforma laboral de 2019, no ha sido uniforme, pues mientras en algunos estados se cuentan con las

\footnotetext{
${ }^{6}$ Publicada en el Diario Oficial de 8 de diciembre de 2001.
} 
reformas constitucionales y las leyes orgánicas de los centros de conciliación, en otros, la reforma todavía no se produce.

La experiencia colombiana que decretó la inexequibilidad de la conciliación administrativa como instancia previa de carácter obligatorio debe ser objeto de estudio y análisis en nuestro país, toda vez que en el ámbito laboral este mecanismo de solución de controversias, no ha tenido el impulso financiero, humano y organizacional necesario para alcanzar los resultados esperados.

Es necesario que la reforma a los textos constitucionales estatales y la expedición de la normativa que materialice la reforma laboral se regule en los plazos establecidos, de manera adecuada y eficaz conforme a la naturaleza y contenido esencial del derecho laboral, a los principios ordenadores de las relaciones laborales y con la intervención de los interlocutores sociales, pues no es un derecho de segunda clase, sino forma parte de la vida misma.

\section{Fuente de consulta}

Constitución Política del Estado de Campeche. Disponible en: http://legislacion.congresocam.gob.mx/. Fecha de consulta: 8 de diciembre de 2019.

Constitución Política del Estado de Coahuila Zaragoza. Disponible en: http://congresocoahuila.bob.mx/portal/leyes-estatales-vigentes. Fecha de consulta: 8 de diciembre de 2019.

Constitución Política del Estado Libre y Soberano de Chiapas. Disponible en: http://www.congresochiapas.gob.mx/new/InfoParlamentaria/LEY_0002.pdf?v=Mzl=. Fecha de consulta: 3 de diciembre de 2019.

Constitución Política del Estado Libre y Soberano de México. Disponible en: http://www.secretariadeasuntosparlamentarios.gob.mx/leyes_y_codigos.html. Fecha de consulta: 8 de diciembre de 2019.

Constitución Política para el Estado de Guanajuato. Disponible en: https://congresogto.s3.amazonaws.com/uploads/ley/pdf/1/CONSTITUCION_POLITICA _PARA_EL_ESTADO_DE_GUANAJUATO_PO_14nov2018.pdf. Fecha de consulta: 4 de diciembre de 2019.

Constitución Política del Estado Libre y Soberano de Nuevo León. Disponible en: https://www.hcnl.gob.mx/trabajo_legislativo/leyes/leyes/constitucion_politica_del_e stado_libre_y_soberano_de_nuevo_leon/. Fecha de consulta: 4 de diciembre de 2019. 
Constitución Política del Estado Libre y Soberano de Morelos. Disponible en: http://marcojuridico.morelos.gob.mx/archivos/constitución/pdf/CONSTMOR.pdf. Fecha de consulta: 5 de diciembre de 2019.

Constitución Política del Estado Libre y Soberano de Nayarit [2018]. Disponible en: http://www.congresonayarit.mx/compilacion-legislativa/\#1499376682502-c554675b148. Fecha de consulta: 6 de diciembre de 2019.

Constitución Política del Estado Libre y Soberano de Oaxaca. Disponible en: http://docs64.congresooaxaca.gob.mx/documentos/legislacion_estatals/Constitucion +Politica+del+Estado+Libre+y+Soberano+de+Oaxaca+(Dto+ref+798+aprob+LXIV+Legis $+18+$ sep $+2019+P O+44+3 a+S e c c+2+n o v+2019)$.pdf. Fecha de consulta: 5 de diciembre de 2019.

Constitución Política del Estado Libre y Soberano de Quintana Roo. Disponible en: http://documentos.congresoqroo.gob.mx/leyes/L176-XV-1910201819/10/2018.pdf. Fecha de consulta: 3 de diciembre de 2019.

Constitución Política para el Estado de Hidalgo. Disponible en: http://www.congresohidalgo.gob.mx/biblioteca_legislativa/Leyes/10Constitucion\%20 Politica\%20del\%20Estado\%20d\%20Hidalgo.pdf. Fecha de consulta: 8 de diciembre de 2019.

Corte Constitucional de Colombia. Sentencia C-160/99, 17 de marzo de 1999. Disponible en: https://www.corteconstitucional.gov.co/relatoria/1999/C-160-99.htm. Fecha de consulta: 3 de diciembre de 2019.

Corte Constitucional de Colombia. Sentencia C-893/2001, 22 de agosto de 2001. Disponible en: http://www.corteconstitucional.gov.co/relatoria/2001/C-893-01.htm. Fecha de consulta: 3 de diciembre de 2019.

Corte Constitucional de Colombia. Sentencia C-417/2002, 28 de mayo de 2002. Disponible en: http://www.corteconstitucional.gov.co/relatoria/2002/C-417-02.htm. Fecha de consulta: 3 de diciembre de 2019.

Cuadra Ramírez, José Guillermo (2002). Medios alternativos de resolución de conflictos como solución complementaria de administración de justicia. México: Suprema Corte de Justicia de la Nación.

Decreto por el que se declaran reformadas y adicionadas diversas disposiciones de los artículos 107 y 123 de la Constitución Política de los Estados Unidos Mexicanos, en materia de justicia laboral. Diario Oficial de la Federación, 24 de febrero de 2017. Disponible

en: 
http://www.dof.gob.mx/nota_detalle.php?codigo=5472965\&fecha=24/02/2017.

Fecha de consulta: 25 de noviembre de 2019.

Ley Federal del Trabajo. Disponible en: http://www.diputados.gob.mx/LeyesBiblio/pdf/125_020719.pdf. Fecha de consulta: 3 de noviembre de 2019.

Ley Orgánica del Centro Federal de Conciliación y Registro Laboral. Diario Oficial de la Federación, 6 de enero de 2020. Disponible en: https://www.dof.gob.mx/nota_detalle.php?codigo=5583502\&fecha=06/01/2020.

Fecha de consulta: 8 de enero de 2020.

Ley del Centro de Conciliación Laboral del Estado de Chihuahua. Disponible en: http://www.congresochihuahua2.gob.mx/biblioteca/leyes/archivosLeyes/1419.pdf. Fecha de consulta: 4 de diciembre de 2019.

Ley del Centro de Conciliación Laboral del Estado de Hidalgo. Disponible en: http://www.congresohidalgo.gob.mx/biblioteca_legislativa/Leyes/Ley\%20del\%20Cent ro\%20de\%20Conciliacion\%20Laboral\%20del\%20Estado\%20de\%20Hidalgo.pdf. Fecha de consulta: 4 de diciembre de 2019.

Ley Orgánica del Centro de Conciliación Laboral del Estado de Campeche. Disponible en: http://legislacion.congresocam.gob.mx/index.php/etiquetas-x-materia/385-leyorganica-del-centro-de-conciliacion-laboral.del-estado-de-campeche. Fecha de consulta: 4 de diciembre de 2019.

Código de Trabajo de Costa Rica. Disponible en: http://www.mtss.go.cr/elministerio/marcolegal/documentos/Codigo_Trabajo_RPL.pd f. Fecha de consulta: 7 de diciembre de 2019.

Ley № 18.572, 1 de Abreviación de los Procesos Laborales. Disponible en: https://parlamento.gub.uy/documentosyleyes/ficha-asunto/37632. Fecha de consulta: 3 de diciembre de 2019.

Ley $\quad$ № $29497 . \quad$ Disponible en: https://www.ilo.org/dyn/natlex/docs/ELECTRONIC/83255/91728/F1395589666/PER8 3255.PDF.pdf. Fecha de consulta: 7 de diciembre de 2019.

Ley 23/1991. Disponible en: https://www.minjusticia.gov.co/po rtals/0/MJD/docs/ley_0023_1991.htm. Fecha de consulta: 3 de diciembre de 2019. 
Martínez V. / Conciliación: Requisito de procedibilidad instituido en la Ley Federal del Trabajo

Ley 640/2001. Disponible en: https://www.oas.org/dil/esp/Ley_ 640_de_2001_Colombia.pdf. Fecha de consulta: 3 de diciembre de 2019.

Ley 712 de $2001 . \quad$ Disponible en: https://www.funcionpublica.gov.co/eva/gestornormativo/norma.php?i=5302.Fecha de consulta: 3 de diciembre de 2019.

Ojeda Avilés, Antonio (2007). Métodos y prácticas en la solución de conflictos laborales: Un estudio internacional. Documento 13. Ginebra: Organización Internacional del Trabajo. 